\title{
Enhanced depth imaging and swept-source optical coherence tomography findings in choroidal osteoma: a case report
}

\author{
Peter Balsnæs · Dorottya Szabo · Agnes Takacs · Andras Papp · Zoltan Zsolt Nagy · Miklos Schneider (D)
}

Received: 13 November 2018 / Accepted: 25 March 2019 / Published online: 11 April 2019

(C) The Author(s) 2019

\begin{abstract}
Summary
Purpose The aim of this study was to report the findings from enhanced depth imaging (EDI) and swept-source optical coherence tomography (OCT) in a choroidal osteoma.

Methods A case study of a patient with choroidal osteoma is presented and discussed.

Results A 25-year-old woman presented with an asymptomatic peripapillary mass. Fundus examination revealed a yellow-orange, well-defined geographical lesion. B-scan ultrasonography, corroborated by fundus autofluorescence (FAF) and OCT findings, pointed to the diagnosis of choroidal osteoma. Calcified areas of the tumor were iso-autofluorescent on FAF and hyporeflective on OCT, revealing the morphological patterns of cancellous bone, including a sponge-like pattern and lines indicating lamellae, Haversian canals, and cement lines. Decalcified patches of the tumor were hypofluorescent on FAF and hyperreflective on OCT and showed overlying retinal damage-most prominently depigmentation and retinal pigment epithelium disruptions. A central area of the tumor revealed unusual characteristics; hyperreflectivity on OCT indicating decalcification but
\end{abstract}

The content of this manuscript has not been published by, or submitted for publication to any other journal. The material of this manuscript was not previously presented at a meeting.

\section{P. Balsnæs}

Faculty of Medicine, Semmelweis University, Budapest, Hungary

D. Szabo $\cdot$ A. Takacs $\cdot$ A. Papp $\cdot$ Z. Z. Nagy $\cdot$ M. Schneider, MD, $\mathrm{PhD}(\bowtie)$

Faculty of Medicine, Department of Ophthalmology,

Semmelweis University, Maria u. 39, H-1085 Budapest, Hungary

schneider.miklos@med.semmelweis-univ.hu isofluorescence on FAF and sharing the same color as the rest of the retina on fundus photography. The area also differed from the other decalcified areas with its cumulus cloud-like appearance. Compared with EDIOCT, SS-OCT images showed some increased definition of the bony features of the tumor, especially in its deeper layers, as well as a mild reduction of the shadowing caused by overlying retinal vessels.

Conclusion The morphological features of a choroidal osteoma are demonstrated using EDI- and SS-OCT. Calcified and decalcified areas of the tumor were differentiated, as well as another area showing unexpected characteristics. In our case, SS-OCT imaging revealed very similar features to EDI-OCT.

Keywords Choroid neoplasms · Osteoma - Optical coherence tomography $\cdot$ Swept-source $\cdot$ Enhanced depth imaging

\section{Ergebnisse erweiterter Tiefenbildgebung und optischer Kohärenztomographie mit Swept- Source-Technologie bei choroidalem Osteom: Falldarstellung}

\section{Zusammenfassung}

Zielsetzung Ziel der vorliegenden Arbeit war die Darstellung der Ergebnisse der optischen Kohärenztomographie (OCT) mit erweiterter Tiefenbildgebung („enhanced depth imaging “, EDI) und der OCT mit SweptSource-Technologie (SS-OCT) bei einem choroidalen Osteom.

Methodik Es handelt sich um eine Fallstudie. Ergebnisse Eine 25-jährige Frau stellte sich mit einer asymptomatischen peripapillären Masse vor. Die Fundusuntersuchung ergab eine gelb-orangefarbene, gut definierte geografische Läsion. Im UltraschallB-Bild, bestätigt durch Fundusautofluoreszenz (FAF) und OCT-Befunde, ergaben sich Hinweise auf die 
Fig. 1 a Fundus photography: a yellow-orange, well-defined geographic lesion. The bulk of the tumor, the calcified part, has an orange-yellow appearance, while the decalcified areas in the periphery of the tumor appear as yellow-white. b Fundus autofluorescence: areas of isofluorescence corresponding with calcification and patches of hypofluorescence in the periphery corresponding with decalcification
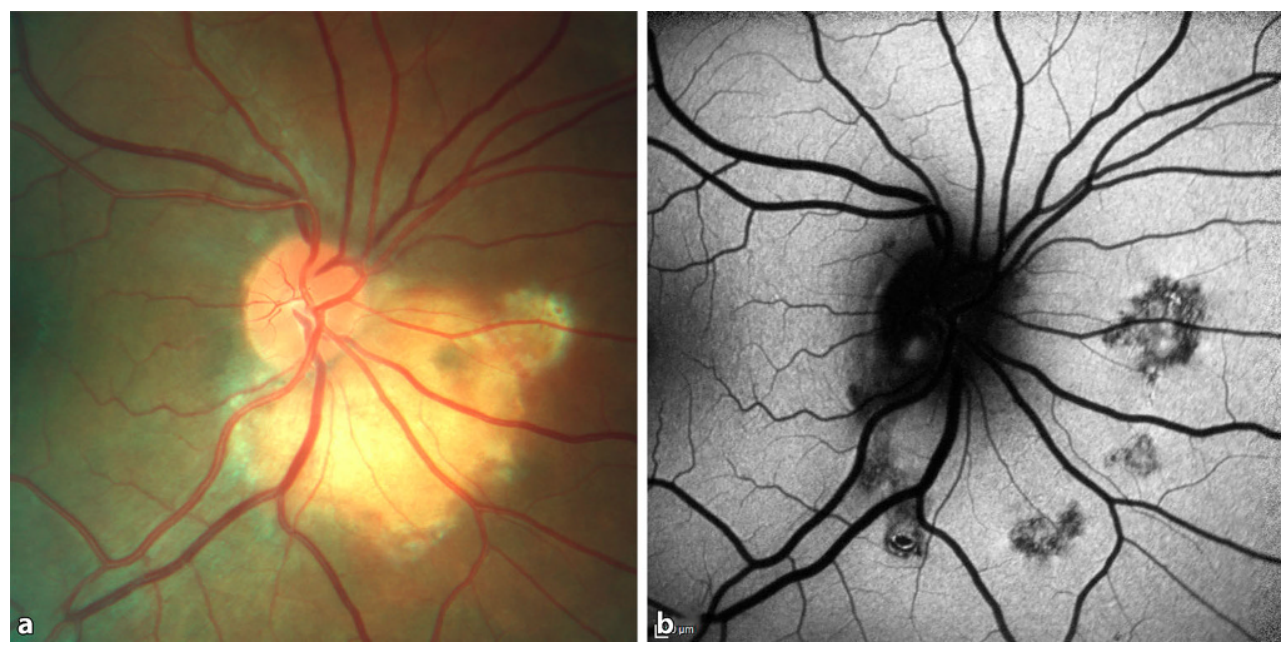

Diagnose eines Aderhautosteoms. Verkalkte Bereiche des Tumors waren in der FAF isoautofluoreszent und in der OCT hyporeflektiv, offenbarten morphologische Muster von spongiösem Knochen, einschließlich eines schwammartigen Musters von Linien, Lamellen, Havers-Kanälen und Zementlinien. Entkalkte Bereiche des Tumors waren hypofluoreszent in der FAF und hyperreflektiv in der OCT. Darüber hinaus zeigten sich Netzhautschäden - am deutlichsten depigmentierte und retinale Pigmentepithelstörungen. Ein zentraler Bereich des Tumors wies ungewöhnliche Eigenschaften auf: Hyperreflektivität in der OCT als Entkalkungszeichen, aber Isofluoreszenz bei FAF, obwohl die Farbe des Tumors in der Fundusfotografie wie die der Netzhaut war. Das Fläche unterschied sich auch von den anderen entkalkten Gebieten mit seinem „cumuluswolkenartigen“ Aussehen. Im Vergleich zur EDI-OCT zeigten SS-OCT-Aufnahmen eine etwas stärkere Darstellung der knöchernen Merkmale des Tumors, insbesondere in den tieferen Schichten, sowie eine leichte Verringerung der Schattenbildung, welche durch darüber liegende Netzhautgefäße verursacht wurde.

Schlussfolgerung Mittels EDI- und SS-OCT können die morphologischen Merkmale eines Aderhautosteoms dargestellt werden. Verkalkte und entkalkte Bereiche des Tumors konnten unterschieden werden sowie ein zentraler Bereich mit ungewöhnlichen Eigenschaften. In dem hier erörterten Fall zeigte die SS-OCT-Bildgebung sehr ähnliche Merkmale wie die EDI-OCT.

Schlüsselwörter Choroidneoplasmen · Osteom · Optische Kohärenztomographie - Swept-Source-Technologie $\cdot$ Erweiterte Tiefenbildgebung

\section{Introduction}

Choroidal osteoma is a rare, benign intraocular tumor comprising mature bone that replaces the choroid [1, 2], often damaging the overlying retina in the process [3]. It typically occurs in young women, as an orange-yellow calcified plaque with sharp margins in the juxtapapillary or macular region [1]. Despite its benign cytology, choroidal osteoma impedes visual acuity in up to $58 \%$ of cases [3], most commonly due to choroidal neovascularization, subretinal fluid deposition, or photoreceptor atrophy [4].

In addition to ultrasonography and computer-assisted tomography, optical coherence tomography (OCT) has been used to identify and study choroidal osteomas. Time-domain OCT (TD-OCT), while useful in assessing damage to the overlying retina, has limited ability to assess the choroid [5-7]. This aspect has been improved upon with spectral-domain OCT (SDOCT) and further with a modification of the former, enhanced depth imaging OCT (EDI-OCT), allowing for a more detailed analysis of the tumor [8-11]. The latest generation of OCT, swept-source OCT (SS-OCT) has facilitated even deeper penetration into tissues with less sensitivity roll-off [12], thereby improving visualization of the choroid.

\section{Case presentation}

A 25-year-old Caucasian woman presented with an incidental finding of an asymptomatic peripapillary mass on fundus examination of her right eye.

Upon the first follow-up examination, her visual acuity, intraocular pressure, and anterior segment findings were unremarkable on both eyes. Fundus examination revealed a yellow-orange, well-defined geographic lesion, nasal and inferior to the optic disc, 4-5 disc diameters in size (Fig. 1a). B-scan ultrasonography showed a highly echogenic lesion with posterior acoustic shadowing. These findings, combined with the suggestive epidemiological factors (young adult, female) prompted the diagnosis of choroidal osteoma. The diagnosis was further corroborated by fundus autofluorescence (FAF) and OCT findings.

The tumor contained both calcified and decalcified areas, the calcified areas being recognized clinically 
Fig. 2 a Enhanced depth imaging optical coherence tomography (EDI-OCT): A peripheral area of the tumor showing decalcification (horizontal arrow). The interior of the tumor is inhomogeneous and a disruption can be seen in the retinal pigment epithelium anteriorly (vertical arrow). b EDI-OCT: Calcified area with a slightly visible lamellar pattern and a central hyperreflective patch (long vertical arrow). A Haversian canal can be seen (short horizontal arrow) and a possible cement line (short vertical arrow). Adjacent to the Haversian canal an area of decalcification is seen with preserved retina lying anterior to it. c Swept-source (SS)-OCT: Calcified area of tumor with a central area of increased reflectivity (short horizontal arrow). The calcified area appears hyporeflective with hyperreflective spots interspersed (vertical arrow). Haversian canals can be seen
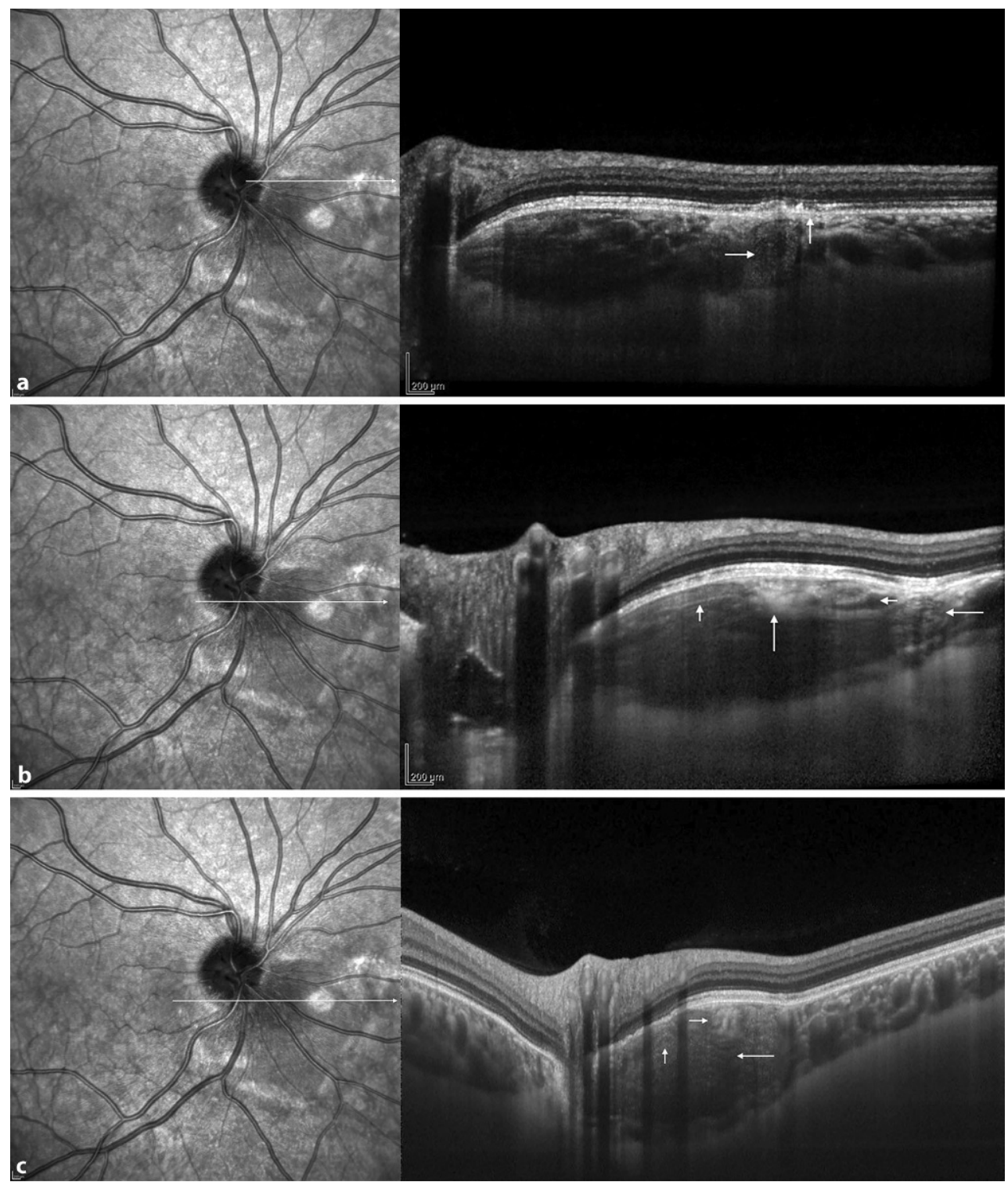

as orange and the decalcified areas as yellow-white [7]. Areas of isofluorescence on FAF corresponded to the calcified areas, while patches of hypofluorescence to decalcification (Fig. 1b), as previously reported by Navajas [9].

Further morphological study of the tumor and the adjacent retina was conducted using both EDI-OCT (Spectralis OCT, Heidelberg Engineering, Heidelberg, Germany) and SS-OCT (DRI OCT-1 Model Triton [plus], Topcon, Tokyo, Japan; Fig. 2).

On EDI-OCT (Fig. 2a,b), the calcified areas of the tumor appeared hyporeflective with interspersed hyperreflective dots, a speckled or sponge-like pattern, resembling cancellous bone. Within the tumor were numerous lines, some hyporeflective, others hyperreflective, reminiscent of lamellae and vascular channels. The retina lying above the calcified area of the tumor was preserved.
The decalcified areas appeared as regions of higher reflectivity, with a decidedly less homogeneous, less organized interior than the calcified areas. Although generally hyperreflective, there were also large spots of hyporeflectivity within. In addition, compared with the largely even surface of the calcified portion, the decalcified regions had a more undulating profile. The overlying retina showed varying degrees of damage, with depigmentation and disruptions in the retinal pigment epithelium (RPE) as the most prominent feature.

Another central area of hyperreflectivity was seen in the tumor. This area was isofluorescent on FAF and showed no damage to the retina anteriorly (Fig. 1b). On fundus photographs this area appeared similar in color to the area surrounding the tumor (Fig. 1a).

On SS-OCT (Fig. 2c), similar patterns in calcified and decalcified areas were found, but with increased 
definition of the tumor's bony features and with slightly less shadowing from overlying retinal vessels.

The patient was followed up for 4 years, during which six sets of OCT images were obtained. Analysis of these images showed no signs of growth, nor did the patient develop any symptoms or complaints.

\section{Discussion}

The first mention of choroidal osteoma in the literature was by Gass, who described the clinical characteristics of the tumor: a slightly and irregularly elevated, yellow-white, choroidal tumor with well-defined geographic borders, covered by RPE with diffuse and mottled depigmentation [1]. The description was later expounded upon, the orange, thicker parts of the tumor were recognized as calcified, while the thinner, atrophic yellow-gray parts were identified as decalcified [7]. Furthermore, using FAF, Navajas recognized calcified areas as isofluorescent and decalcified areas as hypofluorescent [9]. These descriptions corresponded well with the tumor in our case, save for one finding. A central area of increased reflectivity did not appear orange or yellow-white on fundus photo (FP), instead sharing the color with the rest of the retina; on FAF it appeared isofluorescent. This leaves some room for interpretation. One possibility is that it represents a decalcified area that has not yet caused any damage to the overlying retina. Another one may be that it is a lone patch of choroid that has yet to be replaced by tumor tissue.

The spongy architecture in the calcified regions of the tumor as well as its Haversian canals, Volkmann canals, and cement lines have all been described in previous articles [9-11, 13] and-save for Volkmann canals - can also be seen clearly in our case (Fig. 2a,c).

Decalcification of choroidal osteoma was first described by Trimble et al. [14] and was later classified into two patterns by Navajas [9]: (1) hyperreflectivity with lamellar appearance and (2) heterogeneous, hyperreflective, mound-like irregular areas. The tumor in our case contained calcified areas that corresponded more with the latter description, but in places lamellar elements were faintly visible. Here, it is worth mentioning the other area of high reflectivity found centrally in the tumor, previously described. This area also corresponded with the latter description, but was even more disorganized giving a cumulus cloud-like appearance.

The retinal findings in our case are consistent with the clinical picture. As noted, the patient's visual acuity has been unimpaired since the lesion was first diagnosed, indicating that there is no central retinal damage since the tumor did not affect the macular region. At the site of the tumor, OCT images showed relatively few areas of decalcification and only mild damage to the overlying retina.

In an earlier study of 22 choroidal osteomas [7], Shields et al. found that in all cases of decalcification there was damage to the overlying retina. In relation to our tumor, this offers room for interpretation in the case of the central hyperreflective area. A likely possibility though, if this is indeed not just a patch of unencumbered choroid, is that this represents an early stage of decalcification, leaving the overlying retina still intact but also leaving the possibility of damage at a later stage. In any case, any decalcification of a choroidal osteoma is still a still a risk factor for longterm visual loss. In a long-term study by Shields et al. [4], over a 10 -year period, $48 \%$ of cases with decalcification showed poor visual acuity versus $11 \%$ of cases without decalcification. It is worth mentioning that in all cases in which partial decalcification was seen at the first visit, as in our case, there was no further tumor growth. As noted previously, this was also true for our tumor, showing no growth in the 4 years we have followed it up.

Lastly, the SS-OCT images obtained in our case showed an increased definition of the bony features of the tumor, especially in its deeper layers. It should be added here that the tumor in our case was relatively small and that this improvement would perhaps show a greater benefit in a larger tumor. Another favorable feature of the SS-OCT images was a mild reduction of the shadowing caused by overlying retinal vessels compared with the EDI-OCT images. Despite these improvements, however, no new morphological findings were made using this technology. Furthermore, since the clinical significance of this type of tumor is mainly due to the damage it causes anterior to the tumor, the SS-OCT image, at least in our case, was of little value. In conclusion, based on our observations EDI-OCT and SS-OCT show very similar features in a small choroidal osteoma.

Acknowledgements Swept-source OCT was provided by Medicontur Medical Engineering Ltd. The authors have no financial or proprietary interest in any material or method mentioned.

Author contributions PB: literature research, drafting and final approval of manuscript. DS: patient interaction, fundus photography, critical revision and final approval of manuscript. AT: patient interaction, critical revision and final approval of manuscript. AP: patient interaction, patient diagnosis, critical revision and final approval of manuscript. ZZN: critical revision and final approval of manuscript. MS: patient interaction, fundus photography, OCT examinations, patient diagnosis, critical revision, language editing and final approval of manuscript. All authors read and approved the final manuscript.

Funding Open access funding provided by Semmelweis University (SE).

\section{Compliance with ethical guidelines}

Conflict of interest P. Balsnæs, D. Szabo, A. Takacs, A. Papp, Z.Z. Nagy, and M. Schneider declare that they have no competing interests. 
Ethical standards This study was conducted in accordance with the ethical standards stated in the Declaration of Helsinki. The patient was fully informed about the examinations, and provided written consent. Written consent was obtained from the patient for publication of this material. A copy of the consent is available for review.

Open Access. This article is distributed under the terms of the Creative Commons Attribution 4.0 International License (http://creativecommons.org/licenses/by/4.0/), which permits unrestricted use, distribution, and reproduction in any medium, provided you give appropriate credit to the original author(s) and the source, provide a link to the Creative Commons license, and indicate if changes were made.

\section{References}

1. Gass JD, Guerry RK, Jack RL, Harris G. Choroidal Osteoma. Arch Ophthalmol. 1978;96(3):428-35.

2. Williams AT, Font RL, Van Dyk HJ, Riekhof FT. Osseous choristoma of the choroid simulating a choroidal melanoma. Association with a positive $32 \mathrm{P}$ test. Arch Ophthalmol. 1978;96(10):1874-7.

3. Aylward GW, Chang TS, Pautler SE, Gass JD. A longterm follow-up of choroidal osteoma. Arch Ophthalmol. 1998;116(10):1337-41.

4. Shields CL, Sun H, Demirci H, Shields JA. Factors predictive of tumor growth, tumor decalcification, choroidal neovascularization, and visual outcome in 74 eyes with choroidal osteoma. Arch Ophthalmol. 2005;123(12):1658-66.

5. Ide T, Ohguro N, Hayashi A, et al. Optical coherence tomography patterns of choroidal osteoma. Am J Ophthalmol. 2000;130(1):131-4.

6. Fukasawa A, Iijima H. Optical coherence tomography of choroidal osteoma. Am JOphthalmol. 2002;133(3):419-21.
7. Shields CL, Perez B, Materin MA, Mehta S, Shields JA. Optical coherence tomography of choroidal osteoma in 22 cases: evidence for photoreceptor atrophy over the decalcified portion of the tumor. Ophthalmology. 2007;114(12):e53-e8.

8. Freton A, Finger PT. Spectral domain-optical coherence tomography analysis of choroidal osteoma. Br J Ophthalmol. 2012;96(2):224-8.

9. Navajas EV, Costa RA, Calucci D, Hammoudi DS, Simpson ER, Altomare F. Multimodal fundus imaging in choroidal osteoma. Am JOphthalmol. 2012;153(5):890-895.e3.

10. Pellegrini M, Invernizzi A, Giani A, Staurenghi G. Enhanced depth imaging optical coherence tomography features of choroidal osteoma. Retina. 2014;34(5):958-63.

11. Shields CL, Arepalli S, Atalay HT, Ferenczy SR, Fulco E, Shields JA. Choroidal osteoma shows bone lamella and vascular channels on enhanced depth imaging optical coherence tomographyin 15 eyes. Retina. 2015;35(4):750-7.

12. Wojtkowski M, Srinivasan V, Ko T, Fujimoto J, Kowalczyk A, Duker J. Ultrahigh-resolution, high-speed, Fourier domain optical coherence tomography and methods for dispersion compensation. OptExpress. 2004;12(11):2404-22.

13. Hayashi Y, Mitamura Y, Egawa M, Semba K, Nagasawa T. Swept-source optical coherence tomographic findings of choroidal osteoma. Case Rep Ophthalmol. 2014;5(2):195-202.

14. Trimble SN, Schatz H, Schneider GB. Spontaneous decalcification of a choroidal osteoma. Ophthalmology. 1988;95(5):631-4.

Publisher's Note Springer Nature remains neutral with regard to jurisdictional claims in published maps and institutional affiliations. 